\title{
PENGEMBANGAN SSP HOTS UNTUK MENINGKATKAN KARAKTER DAN HASIL BELAJAR PESERTA DIDIK KELAS V SD
}

\author{
Masnur $^{1}$, Nadar ${ }^{2}$ \\ ${ }^{1}$ (Primary School Teacher Education Department,/University Muhammadiyah Enrekang, Indonesia). \\ ${ }^{2}$ (Primary School Teacher Education Department,/University Muhammadiyah Enrekang, Indonesia). \\ * Corresponding Author. E-mail: ${ }^{1}$ masnur1985@gmail.com, ${ }^{2}$ adhar.dikdas14@gmail.com
}

\begin{tabular}{|l|l|l|}
\hline Receive: 12/08/2020 & Accepted: 12/10/2020 & Published: 30/10/2020
\end{tabular}

\begin{abstract}
Abstrak
Penelitian ini bertujuan menghasilkan perangkat pembelajaran berupa Subject Specifik Pedagogy (SSP) berbasis Higher Order Thinking Skills (HOTS) untuk meningkatkan karakter dan hasil belajar peserta didik kelas V SD. Penelitian ini merupakan penelitian dan pengembangan, yang terdiri atas sembilan tahap, yaitu: (1) penelitian dan pengumpulan data, (2) perencanaan, (3) pengembangan draft produk, (4) uji coba lapangan awal, (5) merevisi hasil uji coba lapangan, (6) uji coba lapangan, (7) penyempurnaan produk hasil uji coba lapangan, (8) uji pelaksanaan lapangan dan (9) penyempurnaan produk akhir. Subjek uji coba adalah siswa kelas V SDN 8 Pinrang. Subjek uji coba satu-satu terdiri atas 3 peserta didik. Subjek uji coba kelompok kecil terdiri atas 10 peserta didik yang belum terlibat dalam uji coba satu-satu, dan subjek uji coba lapangan terdiri atas 30 peserta didik kelas V.B. Hasil penelitian ini berupa SSP berbasis HOTS meliputi: silabus, RPP, LKPD, dan lembar penilaian. Hasil validasi ahli menunjukkan berkategori "sangat baik". Hasil uji coba uji coba terbatas yang menunjukkan kategori sangat layak. Kemudian hasil uji coba lapangan, untuk mengetahui kepraktisan SSP HOTS menunjukkan kategori sangat baik dan respon peserta didik melebihi $80 \%$ yang memenuhi kategori baik. Dapat disimpulkan bahwa SSP HOTS yang dikembangan kualitas yang Valid, Praktis dan efektif.
\end{abstract}

Keywords: SSP, HOTS, Karakter

\section{PENDAHULUAN}

Memasuki revolusi Industri 4.0 membawa perubahan besar dalam berbagai bidang kehidupan, tanpa terkecuali pada dunia pendidikan. Untuk menghadapi tantangan dan problem yang makin syarat dengan teknologi dan sains, maka pendidik dituntut menyiapkan peserta didik memiliki Higher Order Thinking Skills (HOTS). Sesuai isi kurikulum 2013 hasil direvisi pada tahun 2017, dimana pembelajaran menekankan HOTS. Dengan demikian pembelajaran hendaknya mengembangkan HOTS agar dapat menyiapkan lulusan yang berkualitas dan mampu bersaing secara global serta menguasai perkembangan teknologi merupakan hal yang penting untuk semua orang bagi masa depan suatu negara (Kanematsu \& Barry, 2016).

HOTS merupakan penggunaan pikiran secara lebih luas untuk menemukan tantangan baru (Heong dkk, 2011). Dengan kata lain HOTS melibatkan keterampilan berpikir dalam mengelolah informasi secara kritis dan kreatif dalam menghadapi dan menyelesaikan masalah yang bersifat kompleks yang dihadapinya. HOTS yang dimiliki oleh seseorang tidak dapat dimiliki secara langsung melainkan diperoleh melalui latihan (Mitri, 2010), sehingga 
perlu dibangun terlebih dahulu jembatan penghubung antara proses berpikir tingkat rendah menuju berpikir tingkat tinggi.

King, Goodson \& Rohani (Kemendikbud, 2018: 36) menjelaskan bahwa untuk menghubungkan antara proses berpikir tingkat rendah menuju berpikir tingkat tinggi dengan membangun skemata dari pengetahuan awal yang telah diperoleh sebelumnya dengan pengetahuan baru yang akan diajarkan. Setelah terpenuhi, maka guru perlu mempersiapkan sebuah situasi nyata yang dapat menstimulasi proses berpikir tingkat tinggi dengan menciptakan dilema, kebingungan, tantangan dan ambiguitas dari permasalahan yang direncanakan akan dihadapi peserta didik.

Penguatan HOTS dalam pembelajaran tentunya tidak terlepas dari penguatan pendidikan karakter. Penguatan Pendidikan Karakter (PPK) merupakan bagian pendidikan di sekolah untuk memperkuat karakter peserta didik. Lickona (1991: 53-62) menekankan pentingnya tiga komponen karakter yang baik (component of good character) dalam mengembangkan pendidikan karakter yaitu: moral knowing atau pengetahuan tentang moral, moral feeling atau perasaan tentang moral, dan moral action atau perbuatan bermoral. Komponen tersebut saling berkaitan, sehingga guru perlu memperhatikan ketika membelajarkan karakter pada peserta didik agar nila-nilai yang ditanamkan tidak sekedar sebagai pengetahuan saja, akan tetapi benar-benar menjadi perilaku atau tindakan.

Memadukan secara seimbang komponen tersebut, peserta didik akan mampu menghayati dan memahami nilainilai luhur. Sehingga pendidikan karakter senantiasa mengarahkan diri pada pembentukan individu bermoral, cakap mengambil keputusan yang tampil dalam perilakunya, sekaligus mampu berperan aktif dalam membangun kehidupan bersama dalam tantangan global. Olehnya itu pendidikan karakter harus dilakukan secara eksplisit (terencana), terfokus dan komprehensif, agar pembentukan masyarakat yang berkarakter dapat terwujud. Dalam rangka merealisasikan penanaman nilai-nilai karkater dapat dilakukan dengan mengintegrasikan pada semua mata pelajaran, sehingga peserta didik di sekolah paham dan memiliki pandangan tentang nilai-nilai yang diajarkan serta mampu mengaplikasikannya dalam perilaku di kehidupan sehari-hari.

Mewujudkan pembelajaran abad 21, guru dituntut untuk memiliki kemampuan mengajar (pedagogy) sekaligus kemampuan penguasaan materi pelajaran (content) yang baik agar dapat mengembangkan karakter dan hasil belajar HOTS peserta didik. Kamin \& Chinedu (2015) menyatakan bahwa higher order thinking (HOT) should be an integral part of teaching and learning, thinking skills lessons should be part of curriculum. Oleh karena itu kemampuan Pedagogy Content Knowledge (PCK) guru sangatlah penting dalam mengintegrasikan Karakter dan HOTS, pada akhirnya mampu merancang strategi pembelajaran yang tepat untuk mengembangkan HOTS dan karakter peserta didik.

\section{California State University}

Northridge (CSUN) (2006: 5) menjelaskan bahwa "subject specific pedagogy, also known as pedagogical content knowledge, is a form of teacher knowledge and a part of a teacher's thinking process". SSP atau dapat dikenal dengan Pedagogy Content Knowledge (PCK) merupakan suatu bentuk pengetahuan guru dan merupakan bagian dari proses berfikir guru, bersifat dinamis, peserta didik memiliki respon untuk bertanggung jawab dengan siapa ia berinteraksi. Karena pengetahuan ini berusaha menjembatani antara pencapaian pengetahuan mata pelajaran dengan perubahan lingkungan dalam pembelajaran, sehingga mengembangkan nilai karakter peserta didik secara bertahap.

Shulman (1986: 9-10) menjelaskan bahwa "Pedagogical content knowledge is an accumulation of common elements; Knowledge of subject matter, Knowledge of students and possible misconceptions, 
Knowledge of curricula, Knowledge of general pedagogy. Selanjutnya, Schmid.D.A., et al. (Masnur, 2017: 89) juga menambahkan bahwa Pedagogy content knowledge is different for various content areas, as it blends both content and pedagogy with the goal being to develop better teaching practices in the content areas. Artinya PCK berbeda dari berbagai bidang isi, karena memadukan baik konten pembelajaran dan ilmu mendidik dengan tujuan untuk mengembangkan praktek pengajaran yang lebih baik dibidang konten baik materi, aktivitas, media, materi, metode, maupun lembar evaluasi belajar.

Berdasarkan pernyataan tersebut, dapat dipahami bahwa PCK merupakan pengetahuan bagaimana menggabungkan antara isi (konten) dan pendidikan secara efektif agar mudah dipahami anak. Pengetahuan guru tentang isi materi saja tidak cukup untuk disajikan kepada peserta didik, sehingga guru memelukan pengetahuan pedagogik untuk mengatur, mengorganisir, menarik dan bisa memberi kemudahan peserta didik. Oleh karena itu perlu adanya penyiapan perangkat pembelajaran berupa Subject specific pedagogy (SSP) berbasis HOTS.

Kenyataan yang terjadi dari studi awal yang dilakukan peneliti di beberapa SDN Kabupaten Pinrang Sulawesi Selatan pada bulan September Tahun 2018, terutama di Kelas V (lima), diperoleh gambaran bahwa beberapa guru masih belum memahami tentang HOTS. Hal ini terlihat dari proses pembelajaran yang dilakukan oleh guru masih dominasi guru di dalam kelas, sehingga pembelajaran menjadi monoton dan peserta didik bergantung penuh pada guru, sehingga peserta didik kurang diarahkan untuk berpikir tingkat tinggi, akibatnya pembelajaran masih bermuatan pada kemapuan mengingat atau hafalan dan pemahaman sederhana.

Sistem penilaian yang dilakukan masih mengutamakan tes tertulis yang terbatas pada pengukuran kemampuan mengingat dan memaham, kemampuan tersebut termasuk dalam keterampilan berpikir tingkat rendah (Lower Order Thinking Skill/ LOTS). Selain itu guru mengalami kesulitan dan keterbatasan pengetahuan dalam mengembangkan SSP berbasis HOTS yang terintegrasi dengan pendidikan karakter.

Berdasarkan analisis kebutuhan dan permasalahan di SD tersebut, dibutuhkan pengembangan SSP berbasis HOTS yang terintegrasi Pendidikan karakter sebagai upaya mempersiapkan peserta didik memiliki HOTS dan karakter, sehingga nantinya mampu memenuhi tantangan dan tuntutan revolusi industri 4.0. SSP yang dikembangkan disesuaikan dengan format yang diadaptasi dari Badan Standar Nasional Pendidikan (BSNP) diantaranya komponen-komponen Subject specific pedagogy meliputi: Silabus, RPP, LKPD dan Lembar Penilaian. Lembar Penilaian ini digunakan untuk melatih peserta didik dalam mengasah kemampuan dan keterampilan berpikir kritis (creative thinking and doing), kreativitas (creativity) dan berkarakter melalui kegiatan latihan berbagai permasalahan nyata dalam kehidupan sehari hari (problem-solving). Soal-soal tersebut sesuai taksonomi Bloom yang telah direvisi yaitu melibatkan kemampuan analisis dan sintesis (C4), mengevaluasi (C5), dan mencipta atau kreativitas (C6) (Krathworl \& Anderson, 2001).

\section{METODE}

Pengembangan SSP HOTS dilakukan dengan metode Research and Development dengan model 4-D. Alur pengembangan model 4-D, yaitu tahap define (pendefinisian), design (perancangan), develop (pengembangan) dan disseminate (penyebaran). Subyek penelitian uji coba lapangan adalah satu orang guru mitra dan peserta didik Kelas VA UPT SDN 8 Pinrang sebagai kelas eksperimen dan peserta didik Kelas VB UPT SDN 8 Pinrang sebagai kelas kontrol.

Data penelitian ini berupa data validasi ahli mengenai kelayakan produk 
yang dikembangkan berupa SSP HOTS, angket penilaian guru terhadap SSP HOTS yang dikembangkan, data angket respon peserta didik terhadap pembelajaran, data hasil pengamatan perilaku berkarakter. Instrumen penelitian ini terdiri dari tiga macam yang digunakan untuk memenuhi kriteria kevalidan, kepraktisan, dan keefektifan produk SSP. Instrumen tersebut adalah: 1) Instrumen untuk mengukur kevalidan SSP, 2) Instrumen untuk mengukur kepraktisan SSP dan 3) Instrumen untuk mengukur keefektifan SSP.

Teknik analisis data dilakukan untuk mendapatkan perangkat pembelajaran berupa SSP HOTS yang valid, praktis, dan efisien. Hasil analisis data diperoleh melalui bukti kevalidan, kepraktisan, dan keefektifan SSP HOTS dilakukan tahapan sebagai berikut; 1) analisis kevalidan SSP berupa SSP HOTS yang dikembangkan yaitu Silabus, Rencana Pelaksanaan Pembelajaran (RPP), Lembar Kerja Peserta Didik (LKPD), dan Lembar penilaian.

Analisis kepraktisan SSP ditentukan dari dua aspek yaitu hasil penilaian guru dan respon peserta didik. SSP HOTS memenuhi syarat praktis apabila kategori minimal pada masing-masing komponen adalah baik. Khusus untuk komponen respon peserta didik, kriteria kepraktisan tercapai apabila jumlah peserta didik yang berkategori baik sejumlah $80 \%$. Penentuan keefektifan SSP HOTS untuk meningkatkan karakter dan hasil belajar peserta didik dilihat dari data hasil observasi dan angket karakter, dan tes hasil belajar peserta didik. Tes hasil belajar peserta didik diperiksa dan dinilai berdasarkan pada tingkatan menganalisis (C4), mengevaluasi (C5), mengkreasi (C6) yang diraih secara individu mencapai Kriteria Ketuntasan Maksimal (KKM) yang telah ditetapkan.

\section{HASIL DAN PEMBAHASAN}

Pengembangan SSP HOTS untuk meningkatkan karakter dan hasil belajar peserta didik kelas V SD dilakukan dengan model 4-D. Berikut ini hasil dari tahapan penelitian dan pengembangan SSP HOTS.

\section{Define (pendefinisian)}

Pada tahap ini dilakukan beberapa analisis diantaranya; 1) Hasil analisis Peserta didik diketahui bahwa, anak pada usia kelas 5 SD berada pada tahap operasional konkret, hal ini sesuai dengan yang dikemukakan oleh Piaget (Berk, 2007: 298) bahwa Concrete operational stage, which extends from 7 to 11 years and marks a major turning point in cognitive development. Thought is far more logical, flexible, and organized than it was earlier. Oleh karena itu usia tersebut sangat baik untuk mengembangkan keterampilan berfikir peserta didik. Selain itu Masnur (2017: 80) menjelaskan bahwa pada masa ini lebih mudah membentuk karakter anak, karena peserta didik lebih cepat menyerap perilaku dari lingkungan sekitarnya dan perkembangan mental anak berlangsung sangat cepat, oleh karena itu lingkungan yang baik akan membentuk karakter yang positif. Berdasarkan hasil analisis peserta didik kelas $\mathrm{V}$ dapat disimpulkan bahwa pembelajaran membutuhkan proses yang dapat mengembangkan keterampilan berpikir tingkat tinggi HOTS dan Karakter peserta didik yang sesuai dengan tahap perkembangannya.

Hasil analisis tugas diperoleh bahwa pada tema "Sehat itu Penting" subtema "Peredaran Darahku Sehat?" dapat dikembangkan karakter dan HOTS peserta didik kelas V SD. Hasil analisis kurikulum diperoleh dari hasil pemetaan kompetensi dasar pada subtema "Peredaran Darahku Sehat?" berupa hasil kompetensi inti, kompetensi dasar dan indicator pada setiap mata pelajaran. Sedangkan hasil analisis materi diperoleh dari hasil analisis kurikulum pada setiap aspek seperti pada aspek Bahasa Indonesia materinya Pantun, aspek IPA Peredaran Darah Manusia, aspek SBdp Tangga Nada, aspek IPS Interaksi Manusia dengan Lingkungan dan aspek PPKn hak, kewajiban, dan tanggung jawab. 


\section{Design (Perencanaan)}

Tahap ini merupakan tahap perancangan komponen SSP berupa Silabus, Rencana Pelaksanaan Pembelajaran (RPP), Lembar Kerja Peserta Didik (LKPD), dan Lembar penilaian. Tahap ini SSP HOTS dirancang sesuai hasil pendefinisian (Define) bahwa SSP sangat perlu dikembangkan dengan mengintegrasikan pendidikan karakter dan HOTS peserta didik. SSP yang dihasilkan pada tahap ini disebut sebagai draft 1 yang selanjutnya akan divalidasi pada tahap pengembangan.

\section{Develop (Pengembangan)}

Tahap pengembangan menjadi empat kegiatan yaitu; 1) Tahap validasi ahli (expert appraisal) dinilai oleh ahli mata pelajaran dan ahli media. Data hasil kevalidan SSP berupa skor dikonversikan menjadi nilai oleh ahli. Hasil uji validasi ahli dapat di lihat pada tabel berikut;

Tabel 1. Hasil kevalidan SSP oleh ahli Mata Pelajaran.

\begin{tabular}{clcc}
\hline No & $\begin{array}{c}\text { Komponen } \\
\boldsymbol{S S P}\end{array}$ & $\begin{array}{c}\text { Total Skor } \\
\text { Aktual }(\mathbf{X})\end{array}$ & $\begin{array}{c}\text { Kategori } \\
\text { Kevalidan }\end{array}$ \\
\hline 1 & Silabus & 52 & Sangat Baik \\
2 & RPP & 85 & Sangat baik \\
3 & LKPD & 48,5 & Sangat baik \\
4 & Lembar & 87 & Sangat baik \\
& Penilaian & & \\
\hline
\end{tabular}

Tabel 2. Hasil kevalidan SSP oleh ahli Media

\begin{tabular}{clcc}
\hline No & $\begin{array}{c}\text { Komponen } \\
\text { SSP }\end{array}$ & $\begin{array}{c}\text { Total Skor } \\
\text { Aktual }(\mathbf{X})\end{array}$ & $\begin{array}{c}\text { Kategori } \\
\text { Kevalidan }\end{array}$ \\
\hline 1 & Silabus & 50 & Sangat Baik \\
2 & RPP & 85 & Sangat baik \\
3 & LKPD & 48,5 & Sangat baik \\
4 & Lembar & 87 & Sangat baik \\
& Penilaian & & \\
\hline
\end{tabular}

Table 3. Hasil kevalidan Instrumen Kepraktisan SSP oleh para ahli

\begin{tabular}{clcc}
\hline No & $\begin{array}{c}\text { Komponen } \\
\text { SSP }\end{array}$ & $\begin{array}{c}\text { Penilaian } \\
\text { Kelayakan }\end{array}$ & $\begin{array}{c}\text { Kategori } \\
\text { Kevalidan }\end{array}$ \\
\hline 1 & $\begin{array}{l}\text { Lembar } \\
\text { penilaian } \\
\text { guru }\end{array}$ & $\begin{array}{c}\text { Valid dengan } \\
\text { revisi }\end{array}$ & Baik \\
2 & $\begin{array}{l}\text { Angket } \\
\text { respon } \\
\text { peserta didik }\end{array}$ & $\begin{array}{c}\text { Valid dengan } \\
\text { revisi }\end{array}$ & Baik \\
& & & \\
\hline
\end{tabular}

Berdasarkan hasil kevalidan oleh para ahli dapat disimpulkan bahwa SSP HOTS untuk meningkatkan Karakter dan hasil belajar peserta didik kelas V SD yang dikembangkan berkategori "sangat baik". Maka selanjutnya dilakukan tahap uji coba terbatas (developmental testing) untuk memperoleh data terkait SSP yang dikembangkan. Hasil revisi yang dilakukan terhadap SSP setelah melalui uji validitas disebut sebagai draft 2 .

Hasil uji coba berupa data keparaktisan SSP HOTS untuk meningkatkan karakter dan hasil belajar peserta didik diperoleh dari pengisian angket penilaian guru terhadap SSP yang dikembangkan dan angket respon peserta didik terhadap proses pembelajaran. Data hasil penilaian tersebut di konversikan menjadi nilai skala lima seperti yang terlihat pada tabel berikut.

Tabel 5. Hasil Penilaian Kepraktisan SSP Uji Coba Terbatas

\begin{tabular}{clcc}
\hline No & $\begin{array}{l}\text { Komponen } \\
\text { SSP }\end{array}$ & $\begin{array}{c}\text { Rerata } \\
\text { Total Skor } \\
\text { Aktual (X) }\end{array}$ & $\begin{array}{c}\text { Kategori } \\
\text { Kepraktisan }\end{array}$ \\
\hline 1 & $\begin{array}{l}\text { Angket } \\
\text { penilaian guru } \\
\text { Angket respon } \\
\text { peserta didik }\end{array}$ & 219 & Sangat baik \\
2 & 30 & Sangat baik \\
\hline
\end{tabular}

Berdasarkan tabel 5 dapat di simpulkan bahwa SSP HOTS yang dikembangkan berkategori "sangat baik". Maka selanjutnya dilakukan pengukuran keefektifan SSP HOTS dengan melakukan uji coba terbatas. Data hasil pengukuran keefektifan SSP HOTS dapat disajikan sebagai berikut.

Tabel 6. Hasil Penilaian Keefektifan SSP pada Uji Coba Terbatas

\begin{tabular}{llcc}
\hline No & $\begin{array}{c}\text { Komponen } \\
\text { Keefektifan SSP }\end{array}$ & $\begin{array}{c}\text { Rerata Skor } \\
\text { Aktual (X) }\end{array}$ & $\begin{array}{c}\text { Kategori } \\
\text { Keefektifan }\end{array}$ \\
\hline 1 & $\begin{array}{l}\text { Lembar Observasi Penilaian Karakter peserta } \\
\text { didik }\end{array}$ & 30 & Sangat baik \\
& $\begin{array}{l}\text { a. Tanggung } \\
\text { jawab }\end{array}$ & & \\
& b. Percaya diri & 20 & Sangat baik \\
& $\begin{array}{l}\text { c. Bekerjasama } \\
\text { d. Toleransi }\end{array}$ & 15 & Sangat baik \\
2 & HOTS peserta didik & 17 & Sangat baik \\
\hline
\end{tabular}




\begin{tabular}{ccc}
\hline C4 & 33,5 & Tinggi \\
C5 & 23 & Tinggi \\
C5 & 17 & Tinggi \\
\hline
\end{tabular}

Berdasarkan tabel 6 dapat di simpulkan bahwa SSP HOTS pada draf 2 yang dikembangkan dikategorikan sangat layak. Hasil draft 2 setelah diuji coba terbatas disebut draft 3. Draft 3 merupakan produk SSP HOTS yang siap untuk diuji dalam uji coba lapangan. Tahap Uji coba lapangan (field testing) dilaksanakan di kelas VA UPT SDN 8 Pinrang. Uji coba Lapangan dilakukan untuk menguji kepraktisan dan Keefektifan SSP HOTS. Berikut hasil analisis kepraktisan SSP HOTS oleh guru.

Tabel 7. Hasil Penilaian guru terhadap kepraktisan komponen SSP HOTS pada Uji coba lapangan

\begin{tabular}{clcc}
\hline No & $\begin{array}{c}\text { Komponen } \\
\text { SSP }\end{array}$ & $\begin{array}{c}\text { Total Skor } \\
\text { Aktual (x) }\end{array}$ & $\begin{array}{c}\text { Kategori } \\
\text { Kevalidan }\end{array}$ \\
\hline $\mathbf{1}$ & Silabus & 55 & Sangat Baik \\
$\mathbf{2}$ & RPP & 89 & Sangat baik \\
$\mathbf{3}$ & LKPD & 49 & Sangat baik \\
$\mathbf{4}$ & Lembar & 88 & Sangat baik \\
& Penilaian & & \\
\hline
\end{tabular}

Berdasarkan tabel 7 diperoleh pada hasil uji coba lapangan berada pada kategori "Sangat baik", hal ini mengindikasikan bahwa SSP HOTS dinilai praktis digunakan dalam pembelajaran. Selain itu hasil penilaian kepraktisan SSP HOTS oleh peserta didik dapat dilihat pada tabel berikut.

Tabel 8 Hasil Penilaian Peserta didik terhadap SSP HOTS

\begin{tabular}{ccc}
\hline Kategori & Skor & Jumlah \\
\hline$X>33,75$ & Sangat baik & 34 \\
$26,25<X \leq 33,75$ & Baik & 1 \\
$18,75<X \leq 26,25$ & Cukup baik & - \\
$11,25<X \leq 18,75$ & Kurang baik & - \\
$X \leq 11,25$ & Tidak baik & - \\
Total & & 35 \\
\hline
\end{tabular}

Berdasarkan hasil analisis kepraktisan oleh guru menunjukkan kategori sangat baik dan respon peserta didik melebihi $80 \%$ yang memnuhi kategori baik terhdaap SSP
HOTS yang dikembangkan. Oleh karena itu dapat dismpulkan bahwa SSP HOTS untuk meningkatkan karakter dan hasil belajar peserta didik kelas V SD pada uji coba lapangan memenuhi kategori Praktis.

Untuk mengukur keefektifan SSP HOTS dilakukan dengan menggunakan metode quasi experimental dengan desain nonequivalent group pretest-posttest control group design. Subyek penelitian pada uji coba lapangan adalah satu orang guru mitra dan peserta didik Kelas VA dan VB masing terdiri dari 37 dan 35 peserta didik. Berikut ini data nilai HOTS peserta didik dari pretest dan posttest kelas eksperimen dan kelas control

Tabel 8 data HOTS Peserta didik

\begin{tabular}{ccccc}
\hline \multirow{2}{*}{ HOTS } & \multicolumn{3}{c}{ Rata-rata nilai peserta didik } \\
\cline { 2 - 5 } & \multicolumn{2}{c}{ Kelas kontrol } & \multicolumn{2}{c}{ Kelas Eksperimen } \\
\cline { 2 - 5 } & Pretest & Posttest & Pretest & Posttest \\
\hline C4 & 30,5 & 32,7 & 31 & 34,5 \\
C5 & 17.7 & 23 & 17,5 & 25 \\
C6 & 13 & 15.7 & 13,5 & 19,7 \\
\hline
\end{tabular}

Kelas eksperimen menunjukkan peningkatan nilai rata-rata HOTS peserta didik pada tingkatan menganalisis (C4) dari nilai rata sebesar 31 menjadi 34,5 dibandingkan dengan kelas kontrol nilai rata-rata sebesar 30,5 menjadi 32,7. Hal ini berarti bahwa keterampilan berpikir tingkat tinggi (HOTS) peserta didik berkembang dan meningkat selama penggunaan SSP HOTS. Sedangkan pada hasil observasi nilai-nilai karakter peserta didik dapat dilihat pada tabel berikut.

Tabel 9. Data Nilai Karakter Peserta didik

\begin{tabular}{ccccc}
\hline \multirow{2}{*}{ Karakter } & \multicolumn{3}{c}{ Nilai rata-rata karakter } \\
\cline { 2 - 5 } & Kelas kontrol & \multicolumn{2}{c}{$\begin{array}{c}\text { Kelas } \\
\text { Eksperimen }\end{array}$} \\
\cline { 2 - 5 } & Pretest & Posttest & Pretest & Posttest \\
\hline Tanggung & 68 & 78,75 & 68,5 & 89,74 \\
jawab & & & & \\
Percaya diri & 60,66 & 75,77 & 60,50 & 91,45 \\
Bekerjasama & 67,75 & 77,15 & 67,77 & 93,25 \\
Toleransi & 62,5 & 75,5 & 63, & 90,65 \\
\hline
\end{tabular}

Berdasarkan tabel 9 diketahui bahwa nilai rata-rata karakter peserta didik 
pada kelas eksperimen lebih tinggi dibandingkan dengan kelas control. Hal ini menujukkan bahwa penggunaan SSP HOTS dapat meningkatkan karakter dan hasil belajar peserta didik.

\section{SIMPULAN}

Berdasarkan hasil validasi ahli menunjukkan berkategori "sangat baik". Hal ini didukung oleh hasil uji coba uji coba terbatas yang menunjukkan kategori sangat layak. Kemudian dilakukan uji coba lapangan, untuk mengetahui kepraktisan SSP HOTS, hasil analisis kepraktisan oleh guru menunjukkan kategori sangat baik dan respon peserta didik melebihi $80 \%$ yang memenuhi kategori baik terhadap SSP HOTS yang dikembangkan. Oleh karena itu dapat disimpulkan bahwa SSP HOTS untuk meningkatkan karakter dan hasil belajar peserta didik kelas V SD pada uji coba lapangan memenuhi kategori Praktis. Hasil uji coba lapangan untuk mengukur keefektifan SSP HOTS menunjukkan bahwa HOTS peserta didik berkembang dan meningkat selama penggunaan SSP HOTS. Sedangkan pada hasil observasi nilai-nilai karakter peserta didik terjadi peningkatan.

\section{Daftar Pustaka}

[1] Anderson, L.W., dan Krathwohl, D.R. 2001. A Taxonomy for Learning, Teaching, and Assesing: A Revision of Bloom's Taxonom y of Educational Objectives. New York: Addison Wesley Longman, In.

[2] Borg, W.R., Gall, M.D., \& Gall. J.P. (2003). Educational research: an introduction. (7th Ed).New York: Pearson Education. Inc.
[4] Collins, R. (2014). Skills for the $21^{\text {st }}$ Century: teaching higher-order thinking. Curriculum and Leadership Journal, 12(14).

[5] Griffin, P.,McGaw, B., \& Care, E. (Eds.). 2012. Assessment and teaching of 21st skills. New York: Springer Publishing Company.

[6] Heng, Y.C., Joo, C.E., Basri, A.A.M., Leng, H.H., Bari, N.A., Suleiman, R., Som, A.M., Mustafa, S., Mohamed, S.H.O, Yusof, Z.M., Yazid, Z., \& Majid, Z.A. (2002). Integrated curriculum for secondary school (curriculum specification. Science form 2). Kuala Lumpur: Ministry of Education Malaysia.

[7] Heong, Y. M., Widad, J., Kiong, Tee Tze, Razali, M. (2011). The Level of Marzuno Higher Order Thinking Skills among Technical Education Students. International Journal of Social Science and Humanity, vol. 1, No.2.

[8] Kamin, \& Chinedu. 2015. Strategies For Improving Higher Order Thinking Skills In Teaching And Learning Of Design And Technology Education. Malaysia: Universiti Teknologi Malaysia.

[9] Kanematsu, H and M. Barry, D. 2016. Chapter 2: Theory of Creativity. Journal Springer. Page 9-12.

[10] Lickona, T. (1991). Educating for character : how our schools can teach respect and responsibility. Nuw York: Bantam.

[11] Masnur. (2017). Pengaruh SSP tematik terhadap peningkatkan karakter kejujuran dan disiplin peserta didik kelas I SD. Jurnal Prima Edukasia, 5 (1), 2017, 79-90. https://doi.org/10.21831/jpe.v5i1.7745 Thiagarajan, S., Semmel, D.S., \& Semmel, M.I. (1974). Instructional development for training teachers of exceptional children A Sourcebook. Bloomington Indiana: Indiana University. 